\section{Commentary: One size doesn't always fit all}

\author{
Derrick Y. Tam, MD, and \\ Stephen E. Fremes, MD, MSc
}

Cardiac surgeons may use prediction tools like the Society for Thoracic Surgery Predicted Risk of Mortality (STS-PROM) or European System for Cardiac Operative Risk Evaluation (EuroSCORE) II to estimate the risk of mortality and/or major morbidity for commonly performed cardiac surgical procedures. In addition, the American College of Surgeons National Surgical Quality Improvement Program (ACS-NSQIP) developed a universal risk calculator for mortality and morbidity for more than 100 different procedures (from colectomies to coronary artery bypass grafting $[\mathrm{CABG}]) .{ }^{1}$ The estimated risks may be used in patient-physician decision and public (or confidential) reporting of risk-adjusted of surgical outcomes-although the impact of public reporting on actual outcomes remains controversial.

When one compares the different risk prediction models, there are some interesting distinctions to be made. In the STS-PROM model for various procedures, a model was fitted for each procedure of interest whereas in the EuroSCORE and ACS-NSQIP models, one model was developed for a set of procedures and the procedure was treated as a covariate or predictor of the outcome in the model. ${ }^{2,3}$ The latter models may be described as universal or general models. ${ }^{4}$ In cardiac surgery, where mortality can be $<1 \%$, events may be sparse and thus creating a combined model allows for more covariates to be included to improve model performance. This may be appropriate when risk factors are common to the surgical procedures included in the model (for example in EuroSCORE II) whereas less appropriate when the procedures are discrepant (such as the ACS-NSQIP model). Finally,

From the Division of Cardiac Surgery, Department of Surgery, Schulich Heart Centre, Sunnybrook Health Sciences Centre, University of Toronto, Toronto, Ontario, Canada.

Disclosures: Authors have nothing to disclose with regard to commercial support.

Received for publication Dec 30, 2019; accepted for publication Dec 31, 2019; available ahead of print Jan 11, 2020.

Address for reprints: Stephen E. Fremes, MSc, MD, Schulich Heart Centre, Sunnybrook Health Sciences Centre, 2075 Bayview Ave, Room H4 05, Toronto,

Ontario, M4N 3M5, Canada (E-mail: stephen.fremes@sunnybrook.ca).

J Thorac Cardiovasc Surg 2020;160:180-1

$0022-5223 / \$ 36.00$

Copyright (c) 2020 by The American Association for Thoracic Surgery

https://doi.org/10.1016/j.jtcvs.2019.12.093

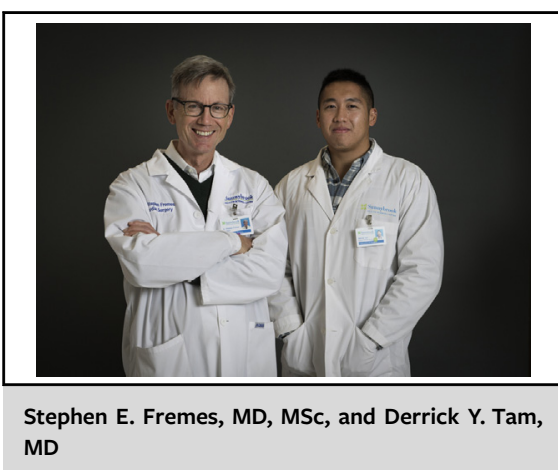

CENTRAL MESSAGE

Estimating procedural risk in

cardiac surgery is complicated

and understanding how risk

models are developed is critical.

universal models like the EuroSCORE can allow surgeons to estimate risk for almost any combination of cardiac procedures, which would not be possible with the STS-PROM score.

In this issue of the Journal, Mori and colleagues ${ }^{5}$ carefully examine the implications of risk prediction using a universal model compared with a procedure specific model. ${ }^{5}$ The investigators purposely chose 3 procedures with very different characteristics: laparoscopic cholecystectomy (high volume, low risk), esophagectomy (low volume, high risk), and CABG (high volume, high risk). The outcome was the concordance statistics (c-statistics), a measure of how well a model performs. A good model typically has a c-statistics $\geq 0.80$. The authors found that their universal model had an overall c-statistic of 0.86 . However, when each procedure was tested on the model developed using all 3 procedures, laparoscopic cholecystectomy performed the best (0.89) compared with CABG (0.77) and esophagectomy (0.71). In this analysis, we note that the overall c-statistics and the c-statistic for laparoscopic cholecystectomies were similar, suggesting that this model was developed mainly on patients undergoing laparoscopic cholecystectomy (which it was), and that the procedure type was predictive of the outcome rather than the patient characteristics being predictive of the outcome. Indeed, in further analyses, the authors developed a model using only esophagectomy and patients undergoing $\mathrm{CABG}$, and the model c-statistics resembled that of a $\mathrm{CABG}$ only model since $\mathrm{CABG}$ was the greater-volume procedure. Relevant to these discussions, in the 2018 European revascularization guidelines, the 
STS-PROM score (Class I) is preferred over the EuroSCORE II (Class IIb) to estimate in-hospital mortality. ${ }^{6}$

Mori and colleagues show that one size certainty may not fit all, and that a critical examination and understanding of the risk prediction models that we use daily is necessary to convey the most accurate message to our patients. Although risk calculators help supplement clinical decision making, the heart team approach is central to optimizing patient selection and ensuring that patients undergo the most appropriate treatment.

\section{References}

1. Bilimoria KY, Liu Y, Paruch JL, Zhou L, Kmiecik TE, Ko CY, et al. Development and evaluation of the universal ACS NSQIP surgical risk calculator: a decision aid and informed consent tool for patients and surgeons. J Am Coll Surg. 2013;217: 833-42. e1-e3.
2. Shahian DM, O'Brien SM, Filardo G, Ferraris VA, Haan CK, Rich JB, et al The Society of Thoracic Surgeons 2008 cardiac surgery risk models: part 1coronary artery bypass grafting surgery. Ann Thorac Surg. 2009;88(1 Suppl): S2-22.

3. O'Brien SM, Shahian DM, Filardo G, Ferraris VA, Haan CK, Rich JB, et al. The Society of Thoracic Surgeons 2008 cardiac surgery risk models: part 2-isolated valve surgery. Ann Thorac Surg. 2009;88(1 Suppl):S23-42.

4. Ad N, Holmes SD, Patel J, Pritchard G, Shuman DJ, Halpin L Comparison of EuroSCORE II, Original EuroSCORE, and The Society of Thoracic Surgeons Risk Score in cardiac surgery patients. Ann Thorac Surg. 2016;102:573-9.

5. Mori MS, Shahian DM, Huang C, Li S, Normand ST, Geirsson A, et al. Surgeons: buyer beware - does 'universal' risk prediction model apply to patients universally? J Thorac Cardiovasc Surg. 2020;160:176-9.e2

6. Neumann F-J, Sousa Uva M, Ahlsson A, Alfonso F, Banning AP, Benedetto U, et al. 2018 ESC/EACTS Guidelines on myocardial revascularization. Eur Heart J. 2019;40:87-165.

7. Patterson T, McConkey HZR, Ahmed-Jushuf F, Moschonas K, Nguyen H, Karamasis GV, et al. Long-term outcomes following heart team revascularization recommendations in complex coronary artery disease. J Am Heart Assoc. 2019;8: e011279.

\title{
Commentary: The risk of risk models
}

\author{
Paul Kurlansky, MD
}

Surgical risk prediction models have had and will continue to have a major impact on surgical decision-making and quality improvement efforts. ${ }^{2}$ However, all risk models are subject to limitation. Perhaps the most important but least discussed limitation of surgical risk models is the fact that they are built on patients who actually underwent surgery, rather than patients who were potentially evaluated for surgery. In other words, every case in the database represents a patient whom a surgeon judged appropriate for surgery. Those who might share the same exact risk profile according to the variables identified in the model but were turned down based on frailty, social situation, or other factors not captured, are not included. The

\footnotetext{
From the Division of Cardiac Surgery, Department of Surgery, Columbia University, New York, NY

Disclosures: Author has nothing to disclose with regard to commercial support.

Received for publication Dec 15, 2019; revisions received Dec 15, 2019; accepted for publication Dec 16, 2019; available ahead of print Jan 7, 2020.

Address for reprints: Paul Kurlansky, MD, Division of Cardiac Surgery, Department of Surgery, Columbia University, Black Building 210, 650 West 168th St, New

York, NY 10032 (E-mail: Pk2245@cumc.columbia.edu).

J Thorac Cardiovasc Surg 2020;160:181-2

$0022-5223 / \$ 36.00$

Copyright (C) 2020 by The American Association for Thoracic Surgery

https://doi.org/10.1016/j.jtcvs.2019.12.063
}

model-derived predicted risk for a prospective patient may not be well correlated with the actual surgical risk for that specific patient. Therefore, risk models tend to be more useful for evaluating surgery performed than for selecting appropriate surgical candidates.

Within this arena of surgical risk prediction, Mori and colleagues $^{3}$ raise an interesting question: does the added power that might be gained by increasing sample size of a combined "universal" risk prediction model misrepresent 